\title{
Homeopathy-A Regulation Therapy Healing Hypo- or Hyper-functions of Pathological Pathways by Magnetic Photons according to the Resonance Principle
}

\author{
Lenger Karin \\ Institute for Scientific Homeopathy, Offenbach D-63065, Germany
}

\begin{abstract}
Since Lenger's detection of magnetic photons in homeopathic remedies by magnetic resonance the mystery of homeopathy comes to a solution. Homeopathy is a regulation therapy curing hypo- and hyper-functions of pathological pathways. It reacts according to the principle of resonance. The fundamental principles of homeopathy as proving, symptom picture, curing according to the Law of Similars and the production of homeopathic remedies over the Avogadro number by repeated dilution and succussion are explained to have the same frequencies so that the resonance principle can work. Pathological pathways are cured by using their highly potentized substrates, inhibitors and enzymes, given daily or each second day. This is in contradiction to the normal applied homeopathy. The efficacy of homeopathy now has a scientific base and is completely explained by applying biochemical and biophysical laws.
\end{abstract}

Key words: Magnetic photons, resonance principle, magnetic frequencies, homeopathic remedies, homeopathic healing.

\section{Introduction}

\subsection{Homeopathy}

In what way does a homeopathic remedy heal? It is known world-wide, that homeopathic therapy cures a lot of people, although there is no material substance left in a highly diluted and succussed homeopathic remedy. The Avogadro-number is transferred when the remedies are manufactured. Potentization, succussion of the vessels after the dilution steps (1:10, D-potencies, 1:100 C-potencies, and Korsakovian potencies: a drop is resting in the vessel being refilled with ethanol to the original volume) is seen with suspicion and with a slight smile. Therefore homeopathy is accused to be of being a humbug, a placebo. Many publications describe very critical [1, 2] and many publications describe successful homeopathy [3, 4]. For years many theories have

Corresponding author: Lenger Karin, Dr. rer. nat., Dipl.-Biochem., research fields: homeopathy, quantum physics, cancer research, enzymic gene regulation dr.karin.lenger@t-online.de existed but no real scientific proof. Additional, the difficulty is that Hahnemann's law of Similars (1796) and the fundamental principles of homeopathy are not really understood $[5,6]$ : (a) the Law of Similars: the patient suffers from his symptoms as if he was poisoned by a certain substance or toxin. The potentized toxin heals the patient's symptoms (like cures like); (b) The symptom picture is obtained by a proving: volunteers poison themselves by a substance/toxin. The symptoms of body and mind are collected to a symptom picture written down in the Materia Medica [7-9], firstly mind symptoms then the symptoms from head to feet follow. It is not usual to consider the biochemical mechanism of the contamination in toxicological books. The homeopathic doctors are only looking for the patient's specific symptoms of body and mind. Firstly they try to find the important psychological symptom which causes the illness of the body; but do not ask for laboratory-values and medical investigations. They search for the only possible remedy curing both psychological symptoms and those of the body 
simultaneously. Then the remedy is given one time and it is expected that the patient will be cured.

If the patient emotionally assures that he feels well again, the homeopath is convinced that the patient is cured. Is the patient really healthy? There is no confirmation of the healing neither by laboratory values nor by medical investigations. That is not scientific.

In clinical cases mostly double blind trials are performed basing on the patients' symptoms. One part of the group gets the verum (remedy) and the other part the placebo [3, 4]. But it is not possible to find people who need the same remedies at the same time, even if they have similar symptoms. Otherwise it is also difficult to determine a reference group of healthy people, because it is forbidden to clone a human being. The same diagnosis would help to get a bigger group of patients and the uptake of laboratory values could control the healing.

Many theories about how homeopathy functions had been developed. It was discussed the memory of water deriving from its structure [10], solitons in water [11-13]. But homeopathic remedies are produced in ethanol [14, 15], a mixture of water and ethanol, which means that in this point of view: the structure of water is senseless. Other authors as Bellavite et al. [16] discussed the biochemical structure and pharmacological reactions as the cause of the efficacy of homeopathy; however the "inverse reaction" is not understood: that a toxin is able to poison a biochemical pathway and to cure as a highly potentized remedy the pathological pathway. Also nanoparticles [17] were the subjects in many conversations about the efficacy of homeopathy. In general, it is a mixture between toxicological and biochemical effects which do neither explain the potency levels nor the homeopathic proving and the curing effect of homeopathy.

\subsection{Biophysics of Living Organisms}

Gurwitch [18] observed that growing onions emit photons stimulating the growth of other onions separated by a quarzglass. A new way of thinking began based on Einstein's formula: $\mathrm{E}=\mathrm{mc}^{2}$ and Max Planck's formula that the Energy of a photon is: $\mathrm{E}=$ hv from which the quantum mechanics is derived: All material and living systems consist of an electromagnetic wave package, a lightpackage. Many scientists began to measure electromagnetic waves in a living organism such as: the Nobel Laureate Herbert Fröhlich [19], C. W. Smith [20], Pokorny and Cifra [21, 22] and many others [23]. Based on Gurwitch experiments F.-A. Popp [24] discovered that living organisms emit photons, biophotons, and take up photons from the sun and the universe. At that moment of uptake the light is at the border of laser. The emitted photon patterns of different sorts of living organisms had been measured by Popp's photomultipliers. His colleagues Roeland and Eduard van Wijk, Bajpai and Cifra measured different photon patterns from individuals before meditation and after meditation and even from ill persons [25-27]. Popp developed a quantum physical model [28] of Health and Disease: living organisms emit and take up photons all the time. A healthy living organism always has $50 \%$ stimulated states. An ill organism has more than $50 \%$ stimulated states from the uptake of too many photons or too many photons emitted below the limit of $50 \%$ e.g. in the case of cancer [28].

Popp could not solve the mystery of how to cure too many photons or how to replace the lacking photons in a biological system. Once he proposed that homeopathy must be an energy and must work according to the resonance principle. However he could not prove that.

It was Theodor Förster [29] who said in 1946 that each chemical reaction works on higher energetic levels by the uptake of photons. Voiekov [30], the grandson of Gurwitch, measured photons during chemical reactions which are in agreement with Förster's research and Popp's ideas. The enzymes in living organisms also need photons as energy for 
enzymic reactions working on higher energy levels of the atoms.

\section{Methods}

\subsection{Measurements of Highly Potentized Homeopathic Remedies}

It was by luck that Karin Lenger listened to a speech by Konstantin Meyl [31] about two Tesla-flatcoil-systems and their abilities to form longitudinal waves at $2.06 \mathrm{MHz}$ and $6.9 \mathrm{MHz}$ between their antennas (antenna near-field-region). Suddenly she had the idea that an experiment with homeopathic remedies using these Tesla-coils must be successful based on Popp's ideas that homeopathy must be an energy [28] in the long wave region. The trials were started together with Josef Ambrusch, Werner Schwille, and Manfred Spielmann.

\subsection{Tesla-flatcoils}

Method [32]: All measurements had been performed in a big Faraday cage $10 \times 12 \mathrm{~m}^{2}, 86 \%$ damping, in the factory of Schwille Elektronik, Benzstr. 1A, D-85551 Kirchheim/ München, and Josef Ambrusch Josef Ambrusch, Ludwig-Ganghofer-Str. 16, D-85551 Kirchheim/ München, Germany.

The Tesla-flatcoil-system is protected by patent; patent holder is Werner Schwille producing them according to Tesla's patent No: 645,576/1900 Complete patents (Tesla book Company 1983). The Tesla-flatcoil-system consists of a sender and a receiver double-flatcoil; in the middle of the coils there are $30 \mathrm{~cm}$ high antennas. Between them, a nearfield antennas-region, longitudinal waves, photon waves, are formed at a distinct frequency. The primary coil with $1 \frac{1 / 2}{2}$ windings, $1 \mathrm{~cm}$ below the secondary coil, gets the electromagnetic field of 6.9 $\mathrm{MHz} / 7 \mu \mathrm{V}$ from a Signal Generator (SML, Rohde \& Schwarz). Orthogonal to the Tesla-coil-system a magnetic Loop-Antenna, Ø 1 m, (HFH2-Z2, Rohde \& Schwarz) measures the magnetic field over it. Only the Loop-Antenna was connected to the spectrum analyzer (FSP 40, $9 \mathrm{kHz}$ - $40 \mathrm{GHz}$, Rohde \& Schwarz). Special cables were used so that their electromagnetic fields could not be measured.

For the measurements of the E- and H-fields on the secondary Tesla-coils a probe set for E-and H-near-field measurements HZ-14 (9 kHz to $1 \mathrm{GHz}$, Rohde \& Schwarz) were used to measure the distribution of the $\mathrm{H}$-and the E-field on the secondary Tesla-coil from the border to the coil's centre.

Only two Tesla-flatcoil-systems were available, one bigger coil producing longitudinal waves of about $2.06 \mathrm{MHz}$ and a smaller one producing longitudinal waves of about $6.9 \mathrm{MHz}$. When only the diode at the receiver coils gave light longitudinal waves were formed. When both diodes at sender and receiver coil emitted light, Hertz waves were there. A quartz vessel containing 4,8 , or 16 saccharose globules of a homeopathic remedy or as reference (pills size 3 ) had been laid at 2-3 $\mathrm{cm}$ from the border of the secondary coil (sender-coil). The magnetic loop antenna connected to the spectrum analyzer measured the magnetic field over the Tesla-coils before and after the magnetic resonance effect caused by homeopathic remedies.

\subsection{DL (Delayed Luminescence), Using a Modified Photomultiplier}

The measurements had been performed in the International Institute of Biophysics, Director: Fritz-Albert Popp, ehemalige Raketenstation, Kapellener Strasse, D-41472 Neuss, Germany.

Method [33, 34]: The measuring cell of the photomultiplier is a Faraday cage: the photondetector is at the top of the cell. At its bottom, the optic cell of quartz contained 16 globules of a highly potentized remedy or 16 saccharose globules as reference; or 40 $\mu \mathrm{L}$ of the ethanolic dilution of a homeopathic remedy or $18 \%$ ethanol as reference in $1 \mathrm{~mL}$ ethanol. The usual stimulation with visible light $(250-800 \mathrm{~nm})$ was altered by 20 windings with a copper wire around the Faraday cage which was connected with an oscillator, 
giving a big constant electromagnetic field of $2.06 \mathrm{MHz} / 50 \mathrm{~V}$. It was assured that some of that field penetrated the cell and was able to separate the photons from the homeopathic remedies.

After stimulation with the electromagnetic field DL took place. The equation developed by Bajpai/Popp is derived from the Hamiltonian equation [35, 36].

$$
n(t)=B_{0}+\frac{B_{1}}{\left(t+t_{0}\right)}+\frac{B_{2}}{\left(t+t_{0}\right)^{2}}
$$

The number of photons, the parameters of that equation, had been calculated with an iterative algorithm in MatLab 7 using the number of counts per bin(5 min) from the measurements: $\mathrm{B}_{0}$-value shows the number of photons at the stimulation point, $B_{1}$-value describes the number of photons emitted from living organisms, Biophotons, and the $\mathrm{B}_{2}$-value means the number of photons separated from the homeopathic remedies between CMK and MMK potencies.

\section{Results}

A. Tesla-coil [32]: it was surprising that the magnetic field (H-field) at the edge of the secondary coil was exactly separated from the E-field in the middle of the coil. It is a surprising result that an isolated magnetic field is produced on the secondary Tesla-coil by Faraday induction .It is also a surprising fact that the measurement of homeopathic remedies is only possible when they have been laid into the magnetic field of the sender-Tesla-coil; then longitudinal waves of magnetic photons are in the near-field antenna region. The magnetic loop antenna measured the magnetic field round the Tesla-coil-system. Magnetic resonance effects are only possible under the condition that the frequency of the homeopathic remedy and that of the Tesla-coil system are the same. Magnetic photons of the homeopathic remedies could be separated from their carrier substance, ethanol or saccharose. Finally, it was possible to measure the potency levels of homeopathic remedies from $200 \mathrm{D} / \mathrm{C} / \mathrm{K}$ remedies to MMK. Each potency level is characterized by a specific magnetic resonance field separating the photons. Increasing fields (increase of $\mu \mathrm{V}$ ) separate magnetic photons from increasing potencies. After that saccharose globules had been shown free of photons by the uptake of their spectrum. This was the same as that of the reference globules. For the first time, frequency spectra of Argentum metallicum CMf and of Cantharis CMf (Fincke-method) had been measured of about $6.9 \mathrm{MHz}$ by a trick: For the uptake of a frequency spectrum a stimulation is necessary. It was detected that the photons of homeopathic remedies have several resonance frequencies from the visible region to the $\mathrm{MHz}$ region. Argentum metallicum CMf and Cantharis CMf also had a resonance frequency of about $2.06 \mathrm{MHz}$ (later on also in the kHz-region unpublished) and of course in the visible region. Therefore, the remedy was laid into the magnetic field of the Tesla-flatcoil having 2.06 $\mathrm{MHz} / 4 \mu \mathrm{V}$ for the use of stimulation. The spectrum analyzer showed firstly an empty window field in the MHz-region of about 6.9 MHz. Slowly regulation of the magnetic field by increasing $\mu \mathrm{V}$, the frequency spectrum of Argentum met CMf was seen, in a second separated trial that of Cantharis CMf. Of course the spectrum of the reference globules showed a spectrum of the background. Using homeopathic remedies having no resonance frequency at $6.9 \mathrm{MHz}$ or 2.06 $\mathrm{MHz}$ only background values had been obtained. It is concluded that a homeopathic pharmacy means a pharmacy of frequencies.

B. DL [33, 34]: This second method confirms again that photons of homeopathic remedies could be separated from the carrier substance, saccharose or ethanol by their resonant frequency field. It is assumed that this field is the magnetic field because the trials with the Tesla-coils showed that the electric field did not react. The $\mathrm{B}_{2}$-value of Bajpai's equation shows the remedies' photons to be holistic. A further assumption is that these photons are the magnetic ones, 
while those of the $\mathrm{B}_{1}$-value, called biophotons by Popp, are the electric ones. During measuring the $B_{2}$-values of the homeopathic remedies the $B_{1}$-values were nearly those of the background and vice versa. Using DL the potency levels could be measured from CMK to MMK. But there is a difference to the measurements with the Tesla-coil-system: The high resonating frequency field is kept constant and another surprising result was obtained. The number of photons ( $B_{2}$-value) characterizes the potency level: about 1,500 photons are specific for a CM-potency, 8,000 photons for an MMK-potency. By error Cantharis CMK was measured at a frequency of $2.006 \mathrm{MHz}$, no photons were detected; but only the background was measurable.

When the frequency is reduced to $1.823 \mathrm{MHz}$ it is possible to measure photons from Arnica CMK, so the new found resonance frequency of Arnica CMK is $1.823 \mathrm{MHz}$. Later on a new Tesla-coil-system with $1.823 \mathrm{MHz}$ resonance frequency was available and Arnica CMK could also be measured by this system (unpublished). Also unknown homeopathic remedies, sent instead of the ordered ones, could be identified by DL. Several potencies of Argentum metallicum between CMK and MMK, had been sent. This is a calibration curve to identify the potency levels of Argentum metallicum. The factory confirmed these measurements. It could be proved that all photons of an ethanolic homeopathic dilution are transferred to saccharose globules during manufacturing. The stability of ethanolic homeopathic dilutions is weak. During one month 2/3 of photons are lost. Homeopathic saccharose globules are more stable over one year. Then the photons go away slowly. A potency level between MK and XMK is obtained after a storage of three years when starting with a CMK potency. The bigger magnetic field of the saccharose molecule keeps its potency level more than one year whereas the weaker magnetic field of the smaller molecule ethanol is not able to keep the photons for more than 2-3 weeks.

\section{Discussion}

\subsection{Magnetic Photons}

After Lenger's detection of magnetic photons in highly potentized remedies since 2006 [32-34], there is another way open to a scientific base of homeopathy in biophysics and biochemistry. For many years physicists have said that magnetic photons do not exist. The Nobel laureate Abdus Salam, predicted the existence of magnetic photons in 1966 [37]. In 2016 magnetic photons, monopoles + and -, had been detected at the CERN Institute in Geneva [38, 39]. Finally, this is a confirmation of Lenger's findings [32-34].

Ruzic and Jerman described in 2009 [40] how the magnetic south monopole influenced the growing of Castanea Sativa mill. Concerning this point, homeopathic remedies might also be magnetic monopoles. It can be assumed that highly potentized remedies become magnetic monopoles, perhaps south poles, with their resonance frequencies and heal pathological pathways. Also, other authors describe the influence of $7 \mathrm{MHz} / 10 \mu \mathrm{T}$ participating in oxygen and $\mathrm{H}_{2} \mathrm{O}_{2}$ biochemical pathways [41]. Lisa et al. [42, 43] influenced the growth and development of hypophysis with the magnetic field of $\mathrm{Ca}^{++}$-ions $7 \mathrm{~Hz} / 100 \mu \mathrm{T}$. Avians have a magnetic field guiding them to the warm regions in winter dependent on the magnetic field lines of the Earth [44].

Concerning acupuncture, Hsieh [45] described resting state fMRI studies. The sustained effect was observed after stimulation by the laser acupuncture of acupoint-K1. This effect was found in the brain region, in anterior insula.

In short, magnetic fields have an important function in living systems. Research of magnetic fields will explain their function in living organisms. It is a task to enlighten homeopathy and acupuncture. Homeopathy with its magnetic photons has a big function in curing pathological pathways. From the proof of the magnetic photons by magnetic resonance 
methods it can be concluded that homeopathy works also by magnetic resonance in an ill body. Popp's model of illness says that in this state too many photons have been uptaken e.g. under stress situations or too many photons have been emitted and ground states of the atoms are achieved in the case of cancer [28]. The healthy normal energy pattern containing 50\% excited states has to be achieved again. The magnetic photons in homeopathic remedies are able to solve this problem. They can attenuate too many photons and they are able to fill up the lack of photons by resonance. Then the pathological pathway will be cured to become the normal function of the biochemical pathways. The ill making photons are supposed to be emitted as biophotons. Therefore, homeopathy is a regulation therapy curing hypo- or hyper-function of a pathological pathway.

\subsection{A Biophysical Explanation of the Fundamental Principles of Homeopathy}

Between the fundamental principles of homeopathy it must be a common base: proving, symptom picture, homeopathic remedy and curing according to the Law of Similars [5, 6]. Lenger has converted the Law of Similars into the following sentence: the frequencies of the patient must match the frequencies of the remedies. Then magnetic resonance takes place. The fundamental principles of homeopathy [46] have their base in common frequencies which can make resonance. In the homeopathic proving the volunteer develops the frequencies I-V and pathological symptoms by poisoning with a substance/toxin. The homeopathic remedy is produced by continuous dilution and succussion creating the frequencies e.g. I-V. The ill patient has symptoms as if a certain toxin has poisoned him; he creates the frequencies I-V and of course the appropriate pathological pathway. Now resonance is possible: the homeopathic remedy can heal the volunteer of the proving and the patient by resonance shown in Table 1. An example: A honey bee stings a volunteer and hot, red oedema are developed; a patient has a swollen hot, red oedema caused by gout. So the homeopathic remedy Apis mellifica (potentized from ethanolic extract of the honey bee) heals the volunteer as well as the patient by resonance because of their common frequencies.

\subsection{Production of Homeopathic Remedies}

The mode of potentization is a mystery for centuries. Lenger [33, 34] detected that the number of photons determines the potency level. In low potencies there are a low number of photons, which means that the number of succussions is low; in high potencies the number of photons is very high meaning that the number of succussions is high. In which way are so many photons produced by succussion and dilution? The following proposal may solve that problem. Really there exists a simple physical law: the Piezo effect which is described to be more effective by Alberto Carpinteri [47]. Vibration pressure and succussions are the same: a material substance is misformed in its structure, dipoles are formed, then an electric voltage, and finally an electromagnetic field. Of course this electromagnetic field includes a magnetic

Table 1 Efficacy of homeopathy consequences from the experimental data, model.

\begin{tabular}{|c|c|}
\hline Fundamental principles of homeopathy & Common frequencies \\
\hline $\begin{array}{l}\text { Proving: poisoning by a substance with frequency I .The volunteer } \\
\text { develops the following frequencies }\end{array}$ & I, II, III, IV, V \\
\hline $\begin{array}{l}\text { The ill person having symptoms as if substance I with frequency I } \\
\text { has poisoned him has the following frequencies }\end{array}$ & I, II, III, IV, V \\
\hline $\begin{array}{l}\text { Homöopathic Potency of the substance with frequency I has the } \\
\text { following frequencies }\end{array}$ & I, II, III, IV, V \\
\hline Healing according to the resonance principle. & \\
\hline $\begin{array}{l}\text { The homeopathic remedy is able to cure the ill volunteer as well as } \\
\text { the ill person. } \\
\text { Both have the same frequencies. }\end{array}$ & $\begin{array}{l}\text { The Law of Similars according to Hahnemann } \\
\text { Lenger: the ill person has the same frequencies as the remedies }\end{array}$ \\
\hline
\end{tabular}


field. In this situation photons are emitted from the original substance. A nuclear fission could happen without any dangerous radiation as Carpinteri says [47]. This may explain the formation of magnetic photons during the production of homeopathic remedies by repeated succussions of a diluted substance. From another point of view Marcin Molski [48, 49] writes: "On the basis of the first- and second-order Gompertzian kinetics it has been proved that the crystallization and its reciprocal process of dissolution belong to the class of quasiquantum non-local coherent phenomena. Hence, there exists a direct link to homeopathy: molecules of the remedy prepared in the process of dilution of the active substance are non-locally interconnected at-a-distance. The results obtained provide strong arguments justifying formulated ad hoc macroscopic versions of quantum non-locality, entanglement and coherence employed in interpretation of the homeopathic remedies activity and effectiveness. In particular they are consistent with the predictions of the weak quantumtheory developed by Atmanspacher and coworkers.” Gerald Pollack [50] investigated water and observed that water can bind photons of the sun's environment. Of course the ethanol/water mixtures of homeopathic dilutions are concluded that the photons produced by dilution and succussion can bind magnetically to the water/ethanolic molecules, even to saccharose and other molecules with a higher molecular weight. In consequence the stability of the homeopathic saccharose globules is probably caused by the bigger magnetic field of saccharose. Pollack says that the water molecule is the carrier of the photons which are brought into the whole world by this method. The photons are slowly emitted from the water molecule. The same happens with dilutions of the homeopathic remedies. The stability of them is very low, after one month only a third of the photons are resting in the ethanolic dilutions. In saccharose homeopathic remedies the potency levels are more stable over $1 \frac{1}{2}$ year [34].
Body and mind is one based on Einstein's equation; a living organism is an electromagnetic wave package. Therefore in homeopathy it is not necessary to look for a psychological symptom before a symptom of a body. If there are leading psychological symptoms or a symptom of the body they can be equally used to find the similar remedies. For example: the main symptom of Silicea [7-9] is: to feel better in warm temperature; the psychological symptom is: to feel better with love, the corresponding mind symptom of warmth. The symptoms of the body have to be transferred into psychological symptoms. The remedy cures both simultaneously.

\subsection{A Biochemical Explanation of the Fundamental Principles of Homeopathy}

Symptom picture: a substance/toxin poisons a healthy volunteer. He develops symptoms in both body and mind. Simultaneously a distinct biochemical pathway is poisoned which biochemical efficacy is described in the books of toxicology. The developed symptoms in body and mind are described as a symptom picture in the Materia Medica [7-9] which is only important for the homeopath. But the biochemical efficacy and the symptom picture belong together to judge the state of a patient based on his laboratory values. Depending on the genetic heredity of the volunteers an ill state is created: either a hyperfunction or a hypofunction of the poisoned biochemical pathway; the enzymes are inhibited or stimulated too much. Nearby also psychological symptoms are developed: the volunteer is crying in panic or he is in a total depression. The polarity of the symptoms mentioned in the Materia Medica [7-9] in a specific symptom picture indicates that behaviour. During that poisoning the frequencies I-V are created. The volunteer is now ill and a distinct biochemical pathway is poisoned described in the books of toxicology. The highly potentized substance/toxin having the frequencies I-V can only cure that distinct pathological pathway of a patient who has the 
frequencies I-V and the corresponding psychological symptoms. That means holistic healing. The homeopaths are content when the patient says that his symptoms have vanished. It is only his feeling without any proof. During a chronic disease several biochemical pathways are involved one after another. The first one does not synthesize its product which is substrate for the next enzyme which cannot work enough because there is a lack of substance and so on. Karin Lenger developed sequences of the pathological pathways [51-54] whose substrates, inhibitors and enzymes could be applied as highly potentized homeopathic remedies as in Hashimoto thyroiditis, in the case of asthma to cure the respiration chain, or in the case of paralyses and rheumatic diseases [51-54]. It is a facility for the finding of curing homeopathic remedies. The conclusion is that the knowledge of biochemical pathways can be applied in homeopathic curing. It could be shown [51-54] that the laboratory values became normal.

Examples: Paralysis with pain is caused by disturbing the functions at the pre- and post-synapses of the nerves. After a bite from a cobra, the cobrotoxin as an irreversible inhibitor inhibits the binding of the substrate acetylcholine to the acetylcholine-receptor. The action potential cannot be transferred, paralysis of the muscles follow and then death. Atropine is a reversible inhibitor of acetylcholine-receptor, the paralysis is reversible. Atropine is used to enlarge the pupils of the eyes (ophthalmic surgeon). Patients with paralysis concerning the acetylcholine-receptor, the highly potentized remedies in $50 \mathrm{M}$, venom of cobra, called Naja tripudians, Atropine or Belladonna (containing atropine) and Acetylcholine cure the nervsynapsis by application twice daily or more. The action potential can be now transferred. If this therapy is not sufficient an additional homeopathic remedy can be applied. The venom of black mamba, potentized it is called Dendroaspis polylepis, causes the deadly paralysis in the following way: the venom contains an irreversible inhibitor of acetylcholine esterase at the back of the acetylcholine receptor, postsynapsis. With this enzyme acetylcholine is split into the acetylresidue and choline, a precious nitrogen base. After splitting both are transported to the presynapsis where acetylcholine is synthezised by using $\mathrm{Ca}^{++}$-ions as catalysators. The potentized Dendroaspis polylepis regenerates acetylcholine-esterase. For better support of the nerve, highly potentized Kalium carbonicum and Natrium muriaticum can be applied to helping natrium/potassium ATPase to pump $\mathrm{K}^{+}$-ions out of the nervecell and then $\mathrm{Na}^{+}$-ions flow into the cell. At the next presynapsis $\mathrm{Ca}^{++}$-ions are needed again for the synthesis of acetylcholine. In this way paralyses and rheumatic pain can be cured homeopathically [51, 53].

In the previous century Schüssler started biochemical thinking in homeopathy: "The Salts of Schüssler" [55] work according to their biochemical function in the body. Harisch and Dittmann [56-58] showed reproducible effects of low and highly potentized homeopathic remedies on the activity of different rat liver enzymes. They concluded that homeopathic remedies control enzyme activities. Teixeira [59] began this new way of homeopathic treatment. He used successfully potentized estrogen in endometriosis-associated pelvic pain.

In this way highly potentized substrates, inhibitors and enzymes of the pathological pathway can be used for healing. A further conclusion is that homeopathic therapy can be applied according to the indication, because only one biochemical pathway is poisoned in a volunteer or attacked in a patient at first developing a symptom of the body, an indication for a remedy. Homeopathic remedies can be used according to biochemical laws and according to an indication or an ill laboratory value. The old struggle between Hahnemann and Lutze or between the homeopaths today, to cure according to an indication or holistically is not realistic. It does not exist. The homeopaths refuse biochemical thinking and its application to homeopathic remedies.They say this is not correct 
homeopathy. Therefore, they should not be allowed to

Table 2 Each step means a state of illness and the suitable remedy.

\begin{tabular}{lll}
\hline Steps one after the other & Homeopathic remedy & Symptoms of Materia Medica [7-9] \\
\hline 1 & Aconite nap. & Freezing by cold wind, dry fever, tonsillitis left side \\
2 & Hepar sulphuris & Freezing, no fever, tonsillitis left and right side \\
3 & Silicea & Freezing, no fever, tonsillitis, hard lymph nods \\
4 & Mercurius solubilis & Adhesive sweat, tonsillitis with supporating lymph nodes \\
5 & Lachesis mutus & $\begin{array}{l}\text { Hot sweat, fever, tonsillitis with supporating lymph nodes, difficulties in } \\
\text { swallowing with pain in the ear. }\end{array}$ \\
\hline
\end{tabular}

use the following homeopathic remedies any more involved as substances in important biochemical pathways: Sulphur, Phosphorus, Graphites, Aceticum acidum all the minerals as e.g. Silicea, Calcium carbonicum, Natrium muriaticum, Kalium carbonicum, and the trace elements as Ferrum metallicum, Cuprum metallicum, Zincum metallicum...

\subsection{Chronic Diseases as an Energy Staircase}

But mostly in a chronic disease several biochemical pathways are attacked in the patient, one after another, because they are dependent on each other.

Imaging an energy staircase downwards: each step means a state of an illness and the corresponding remedy shown in Table 2. This energy stair case shows the chronic states of illness starting from the Psoric state with its suitable remedies as Phosphorus, Sulphur to the Sycotic state with its remedies as e.g. Thuja, Nitricum acidum and to the Syphilitic state with its remedies e.g. as Mercurius, Lachesis mutus according to the theory of chronic diseases of Hahnemann [60] and Ortega [61]. Homeopathic curing means to go backwards, to climb up the energy stair case, from the Syphilitic state, Sycotic state to the Psoric state using the corresponding remedies.

Example: the remedies from the Psoric to the Syphilitic state are shown in Table 2 in a case of chronic swollen lymph glands with a disturbed immune system regulated by $\mathrm{Ca}^{++}$-ions. All remedies must be given in several doses, daily till the patient is healthy again.

\section{Conclusions}

Since Hahnemann (1755-1843) homeopaths believe that only one remedy heals the body and mind of the patient simultaneously. To give homeopathic remedies according to an indication is forbidden; this is an old struggle among homeopaths. All of this is no longer true. Homeopathic remedies can be applied one after another. Highly potentized substrates, inhibitors and enzymes of the pathological pathway can be given for curing the patient daily or every second day. Homeopathic healing happens without side effects. In many cases of illness the medical doctors do not give any cures, but homeopathy with its many abilities to heal pathological pathways by the resonance effect may be the preferred therapy. Since Lenger's detection of magnetic photons in homeopathic remedies the efficacy of homeopathy is completely explained and has a scientific base. It reacts in a biophysical and biochemical way according to the principles of Biophysics and Biochemistry.

\section{References}

[1] Posadzki, P., Alotaibi, A., and Ernst, E. 2012. “Adverse Effects of Homeopathy: A Systematic Review of Published Case Reports and Case Series.” Int. J. Clin. Pract. 66 (12): 1178-88.

[2] Shang, A., Huwiler-Müntener, K., Nartey, L., Jüni, P., Dörig, S., and Sterne, J. 2005. "Are the Clinical Effects of Homoeopathy Placebo Effects? Comparative Study of Placebo-Controlled Trials of Homoeopathy and Allopathy.” The Lancet 366: 726-32.

[3] Mathie, R. T., Ramparsad, N., Legg, L. A., Clausen, J., Moss, S., and Davidson, J. R. T. 2017. "Randomised, Double-Blind, Placebo-Controlled Trials of Non-individualised Homeopathic Treatment: Systematic Review and Meta-Analysis.” Systematic Reviews. 6: 63. DOI 10.1186/s13643-017-0445-3.

[4] Witt, C. M., Bluth, M., Albrecht, H., Weißhuhn T., 

Magnetic Photons according to the Resonance Principle

Baumgartner, S., and Willich, S. N. 2007. "The in vitro Evidence for an Effect of High Homeopathic Potencies: A Systematic Review of the Literature." Complementary Therapies in Medicine 15: 128-38.

[5] Hahnemann, S. 1921. Organon der Heilkunst, 6.Auflage. Germany. D-79400 Kandern: Narayana Verlag.

[6] Belavite, P., and Signorini, A. 2002. "The Emerging Science of Homeopathy.” California North. Berkely: Atlantic Books.

[7] Hahnemann, S. 2007. Hahnemanns Arzneimittellehre, Germany. D- 79400 Kandern: Narayana Verlag.

[8] Clarke, J. H. 2007. Der neue Clarke, Germany. D-86926 Greifenberg: Hahnemann Institut.

[9] Phatak, S. R. 2004. Homöopathische Arzneimittellehre. Germany, München: Urban \&Fischer, Elsevier GmbH.

[10] Schiff, M. 1995.“The Memory of Water.” In Homeopathy and the Battle of new Ideas intheNew Science. New York: Harper Collins Publishers.

[11] Popp, F. A. 1998. "Hypothesis of Modes of Action of Homeopathy.” In Energetische Medizin, edited by Heusser, P. Switzerland, Bern: Europäischer Verlag der Wissenschaften, 101-10.

[12] Tschulakov, A. V., Yan, Y., and Klimek, W. 2005.“A New Approach to the Memory of Water.” Homeopathy 94: 241-7.

[13] Elia, V., Elia, L., Cacace, P., Napoli, E., Niccoli, M., and Savarese, F. 2006. “'Extremely Diluted Solutions” as Multi-Variable Systems. A Study of Calorimetric and Conductometric Behaviour as a of the Parameter Time.”J. Therm. Anal. Cal. 84: 317-23. doi: 10.1007/s10973-005-7266-7.

[14] Homöopathisches Arzneibuch HAB. 2009. Germany. Stuttgart: Deutscher Apothekerverlag.

[15] Gaier, H. 1991. "Potentizing Methods." In Thorsons Encyclopaedic Dictionary of Homeopathy. London: Thorsons Harper Collins Publishers, 432-67.

[16] Bellavite, P., Marzotto, M., Olioso, D., Moratti, E., and Conforti, A. 2014. "High-dilution Effects Revisited. 2. Pharmacodynamics Mechanism.” Homeopathy 103 (1): 22-43

[17] Chikramane, P. S., Suresh, A. K., Bellare, J. R., and Kane, G. S. 2010. "Extreme Homeopathic Dilutions Retain Starting Materials: A Nanoparticulate Perspective.” Homeopathy 99: 231-42.

[18] Gurwitsch, A. 1923. "Die Natur des spezifischen Erregers der Zellteilung, Arch.” Entwicklungsmech 100: 11-40.

[19] Smith, C. W. 2002. "Effects of Electromagnetic Fields in the Living Environment.” In Proceedings of International Conference. Electromagnetic Environments \& Health in Buildings, edited by Clements-Croome, D. London: Taylor \& Francis, 53-118.

[20] Smith, C. W. 2006. “Froehlich’s Interpretation of Biology through Theoretical Physics.” In A Physicist Ahead of His Time, edited by Hyland, G. H., Rowland, P., and Herbert Froehlich, F. R. S. Liverpool: The University of Liverpool, 91-138.

[21] Pokorny, J., Hasek, J.,Vanis, J., and Jelinek, J. 2008. "Biophysical Aspects of Cancer-Electromagnetic Mechanism.” Indian Journal of Experimental Biology 46: 310-21.

[22] Cifra, M., Fields, J. Z., and Farhadi, A. 2011. “Electromagnetic Cellular Interactions." Progress in Biophysics and Molecular Biology 105: 223-46.

[23] Kǔcera, O., and Cifra, M. 2015. "Radiofrequency and Microwave Interactions between Biomolecular Systems."
J. Biol. Phys .42
(1): 1-8. doi: 10.1007/s10867-015-9392-1.

[24] Popp, F. A. 2006. Biophotonen-Neue Horizonte in der Medizin. Germany, Stuttgart: KarlF. Haug-Verlag.

[25] Van Wijk, R., van Wijk, E. P. A., and Bajpai, R. P. 2008. "Quantum Squeezed State Analysis of Spontaneous Ultra-Weak Light Photon Emission of Practitioners of Meditation and Control Subjects." Indian Journal of Experimental Biology 46: 345-52.

[26] Bajpai, R. P., Van Wijk, E., Van Wijk, R., and Van der Greef, 2013. “Attributes Characterizing Spontaneous Ultra-Weak Photon Signals.” J. Photochem. Photobiol. B: Biology 129: 6-16.

[27] Cifra, M., van Wijk, E. P. A., Koch, H., Bosman, S., and van Wijk, R. 2007. "Spontaneous Ultra-Weak Photon Emission from Human Hands Is Time Dependent.” Radioengineering 16 (2): 15-9.

[28] Bischof, M. 1995. Biophotonen, Das Licht in unseren Zellen. Germany, Frankfurt: Verlag Zweitausendeins.

[29] Förster, T. 1948. "Zwischenmolekulare Energiewanderung und Fluorescenz.” Annalen der Physik 2: 57-75.

[30] Voeikov, V. L., and Naletov, V. I. 1998. "Weak Photon Emission of Non-linear ChemicalReactions of Amino Acids and Sugars in Aqueous Solutions.” In Biophotons, edited by Jiin-Ju Chang, Joachim Fisch, and Fritz-Albert Popp. The Netherlands, Dortrecht:Kluwer Academic Publishers. ISBN 0-7923-5082-0.

[31] Meyl, K., and Meyl, K. 2003. Elektromagnetische Umweltverträglichkeit Skalarwellen und die technische, biologische wie historische Nutzung longitudinaler Wellen und Wirbel, Teil3, Germany, Villingen-Schwenningen, INDEL GmbH.

[32] Lenger, K. 2006. "Homeopathic Potencies Identified by a New Magnetic Resonance Method.” Subtle Energies and Energy Medicine15 (3): 225-43.

[33] Lenger, K., Bajpai, R.P., and Drexel, M. 2008 ."Delayed Luminescence of High Homeopathic Potencies on Sugar Globuli.” Homeopathy 97 (3): 134-40. 

Magnetic Photons according to the Resonance Principle

[34] Lenger, K., Bajpai, R. P., Spielmann, M. 2013. "Identification of Unknown Homeopathic Remedies by Delayed Luminescence.” Cell Biochemistry \& Biophysics 68 (2): 321-34. doi: 10.1007/s12013-013-9712-7.

[35] Bajpai, R. P., Kumar, S. S., and Sivadasan, V. A. 1998. "Biophoton Emission in the Evolution of a Squeezed State of Frequency Stable Damped Oscillator.” Applied Mathematics and Computation 93: 277-88.

[36] Bajpai, R. P. 2007. “Quantum Squeezed State Description of Spectral Decompositions of Abiophoton Signal and the Possibility of Remote Intervention.” In Biophotonics and Coherent Systems in Biology, edited by Belussov, V. L., Voeikov, V. S., and Mortynyuk, V. S. New York: Springer, 33-46.

[37] Abdul Salam. Available at: https://de.wikipedia.org/wiki/Abdus_Salam.

[38] Alexandre, J., Felea, D., Pavalas, G., Tuszynski, J. A., et.al. 2016. "Search for Magnetic Monopoles with the MoEDAL Forward Trapping Detector in13TeV Proton-Proton Collisions at the LHC.” Physical Review Letters $118 \quad$ (6): 061801. doi:10.1103/PhysRevLett.118.061801.

[39] Bramwell, S. T., Giblin, S. R., Calder, S., Aldus, R., Prabhakaran, D., and Fennell, T. 2009 ."Measurement of the Charge and Current of Magnetic Monopoles in Spin Ice.” Nature 461: 956-60.

[40] Ruzic, R., Jerman, I., Jeglic, A., and Fefer, J. D. 1993. "Various Effects of Pulsed and Static Magnetic Fields on the Development of Castanea Sativa Mill in Tissue Culture.”Electro- and Magnetobiology 12 (2): 165-77.

[41] Usselmann, R. J., Hill, I., Singel, D. J., and Martino, C. F. 2014. "Spin Biochemistry Modulates Reactive Oxygen Species (RSO) Production by Radio Frequency Magnetic Fields.” Plos One 9 (3): 993065. doi:10.1371/journal.pone.0093065.

[42] Lisi, A., Foletti, A., Ledda, M., Rosola, M., Giuliani, E. L., D`Emilia, E., and Grimaldi, S. 2006. "Extremely Low Frequency $7 \mathrm{~Hz} 100 \mu \mathrm{T}$ Electromagnetic Radiation Promotes Differentiation in the Human Epitelial Cell Line HaCaT.” Electromagn. Biol. Med. 25: 269-80.

[43] Timmel, C. R., Till, U., Brocklehurst, B., Mclauchlan, K. A., and Hore, P. J. 1998. "Effects of Weakmagnetic Fields on Free Radical RecombinationReactions." Molecular Physics 95 (1): 71-89.

[44] Ritz, T., Thalau, P.,Phillips, J.B.,Wiltschko, R., Wiltschko, W. 2004. "Resonance Effects Indicate a Radical-Pair Mechanism for Avian Magnetic Compass."Nature 429: 177-80

[45] Hsieh C.-W. 2016."Laser Acupuncture Induced the Alteration in Default Mode Network on Acupoint K1.” Presented at BIT's 3rd Annual World Congress of High-Tech Acupuncture and Integrative Medicine, Nov.
16-19, Nanjing, China.

[46] Lenger, K. 2016. “A Quantumphysical Model of Homeopathic Function.” Presented at the International Discussion Meeting: Förster Resonance Energy Transfer in life Sciences: FRET2, April 3-6, 2016, Max Planck Institute for Biophysical Chemistry, Göttingen, Germany.

[47] Carpinteri, A., Lacidogna, G., Manuello, A., et al. 2013. "Piezonuclear Fission Reactions from Earthquakes and Brittle Rocks Failure: Evidence of Neutron Emission and Non-Radioactive Product Elements.” Exp. Mech. 53: 345. doi:10.1007/s11340-012- 9629-X.

[48] Molski, M. 2011. "Quasi-Quantum Model of Potentization.” Homeopathy 100: 259-63.

[49] Molski, M. 2012. Fractal Time of Life .Germany, D-66121 Saarbrücken: LAP LAMBERT Academic Publishing GmbH\&Co.KG.

[50] Pollack, G. H. 2013. The Fourth Phase of Water: Beyond Solid Liquid, and Vapor. US, New York: Ebner and Sons Publishers. ISBN: 978-0962689536.

[51] Lenger, K. 2010. "A New Biochemical Model of Homeopathic Efficacy in Patients with Chronic Diseases.” Subtle Energies \& Energy Medicine 19 (3): 1-34.

[52] Lenger, K. 2011. Applied Quantum Physics: Pathological Biochemical Pathways Cured by High Homeopathic Potencies. Research Gate. doi: 10.13140/2.1.1651.0725.

[53] Lenger, K. 2015. "Magnetic Photons of Homeopathic Remedies Cured Rheumatic Disease according to Biochemical Pathways.” FEBS Journal 282 (Suppl. 1): 192.

[54] Lenger, K., and Lang, G. 2014. "Photons Detected by Magnetic Resonance Are Efficious in Homeopathy: A Critical Review.” Alternative Medicine 22 (1): 4.

[55] Wacker, S. 2006. In Balance mit Schüßler-Salzen. Germany, Stuttgart: Haug/ MVS Medizinverlage. ISBN 383042230.

[56] Harisch, G., and Kretschmer, M. 1990. Jenseits vom Milligramm. Die Biochemie auf den Spuren der Homöopathie. Germany, Heidelberg: Springer-Verlag.

[57] Harisch, G., and Dittmann, J. 1998. "Unterschiedlicher Einfluß von cAMP-Potenzen und AMPVerdünnungen am Beispiel verschiedener Enzymsysteme.” Biol. Med. 27 (2): 55-62.

[58] Dittmann, J., Kanapin, H., and Harisch, G. 2000. “Einfluß ausgewählter Homöopathika auf die katalytische Aktivität der Urikase, der sauren Phosphatase und der zytosolischen Glutathion-S-Transferasen.” Biol. Med. 29 (3): 125-31.

[59] Teixeira, M. Z., Podgaec, S., and Baracata E. C. 2017. "Potentized Estrogen in Homeopathic Treatment of Endometriosis-Associated Pelvic Pain: A 24-Week, Randomized, Double-Blind, Placebo-Controlled Study.” European Journal of Obstetrics \& Gynecology and 

Magnetic Photons according to the Resonance Principle

Reproductive Biology 211: 48-55.

[60] Hahnemann, S. 1995. "The Chronic Diseases, Their Peculiar Nature and Their Homeopathic Cure.” Tr.L.Tafel republished, B. Jain, New Delhi: B. Jain.
[61] Ortega, S. 1984. Anmerkungen zu den Miasmen oder chronischen Krankheiten im SinneHahnemanns. Germany, Heidelberg: 2. Auflage, Karl F, Haug Verlag. 